\title{
All PT roads led to Rome: Proficiency Testing Workshop
}

\author{
Brian Brookman · Antonio Menditto · Marina Patriarca
}

Published online: 9 April 2009

(C) Springer-Verlag 2009

For 3 days in October 2008, "the eternal city" became the global centre for proficiency testing (PT) and external quality assurance (EQA). Building on the success of their previous workshops, the EURACHEM Proficiency Testing Working Group organised the 6th Workshop on Proficiency Testing in Analytical Chemistry, Microbiology and Laboratory Medicine in association with EQALM and CITAC. The Workshop (www.iss.it/eurachem) was supported locally by several Italian organisations, including the public research institutes devoted to public health (ISS), metrology (INRIM), environmental protection (ISPRA) and innovative technologies (ENEA), as well as the accreditation bodies (SINAL, SINCERT \& SIT) and the standardisation body for chemical industry (UNICHIM).

This workshop once again provided an excellent opportunity for providers, users and regulators of PT/EQA to come together to discuss a wide range of key issues across the three disciplines of analytical chemistry, microbiology and laboratory medicine. With 244 delegates from 47 different countries attending, it ensured that discussions encompassed views on a global perspective. This included important contributions from a number of developing countries which was made possible by the support of delegates from these areas by IAEA, PTB and UNIDO. Many sectors face very similar issues with regards to PT/ EQA so this workshop provided an excellent and beneficial opportunity for cross-fertilisation of ideas.

B. Brookman $(\bowtie)$

LGC Standards Proficiency Testing, Bury, Lancashire, UK

e-mail: Brian.Brookman@lgcstandards.com

A. Menditto · M. Patriarca

Istituto Superiore di Sanità, Rome, Italy
Special attention was given in this event to emerging issues such as the new standard for PT/EQA, the developments of PT/EQA in the European Union, the status and needs of PT/EQA in developing areas of the world and PT/ EQA developments in emerging fields. Enhancements in the organisation of PT/EQA schemes and the end-user perspective of PT/EQA were also addressed. These topics were explored and discussed through a series of lectures and working group discussions.

The workshop was enriched further with 74 poster contributions covering a wide range of topics and experiences concerned with PT/EQA. In conjunction with the workshop, training sessions on "Statistics for PT/EQA Schemes" and "Selection, use and interpretation of PT/ EQA schemes" were provided, which were subscribed by 140 and 130 trainees.

This workshop proved a great success thanks to the hard work of the local organizers and the quality of the presentations and posters. But just as important was the enthusiasm of all the delegates that led to lively debate and fruitful discussions which made this workshop so beneficial. Such a wide range of experiences from around the world provided a good balance of views on current and future practices. We are pleased to issue the papers on many of the presentations, posters and working group discussions in this special issue of the Journal-please note that the paper on the development of the new ISO/IEC 17043 standard has already been published (DW Tholen (2008) Accred Qual Assur 13:727-730).

$\begin{array}{ll}\text { Brian Brookman } & \text { Antonio Menditto, } \\ \text { Guest Editor and } & \text { Marina Patriarca } \\ \text { Chair of Workshop } & \text { Chairs of Workshop } \\ \text { Scientific Committee } & \text { Organising Committee }\end{array}$






The EURACHEM PT WG at the Workshop in Rome (left to right)
Marina Patriarca, Istituto Superiore di Sanità, Italy Ender Okandan, Petroleum Research Laboratory, Turkey Kees van Putten, DUCARES B.V., The Netherlands Miklos Naray, Hungarian Institute of Occupational Health, Hungary

Irma Mäkinen, Finish Environment Institute, Finland Halina Polkowska-Motrenko, Institute of Nuclear Chemistry and Technology, Poland

Brian Brookman, LGC Standards Proficiency Testing, UK

Tracey Noblett, LGC Standards Proficiency Testing, UK Barry Tylee, Health \& Safety Laboratory, UK Antonio Menditto, Istituto Superiore di Sanità, Italy Michael Koch, Universität Stuttgart, Germany Piotr Robouch, Institute for Reference Materials and Measurements, EU 